\title{
Slowing down in the fast lane: could this be sinus tachycardia?
}

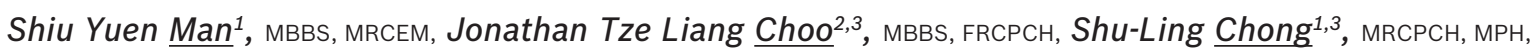
Ronald Ming Ren $\underline{\operatorname{Tan}}^{1,3}$, MBBS, MRCPCH

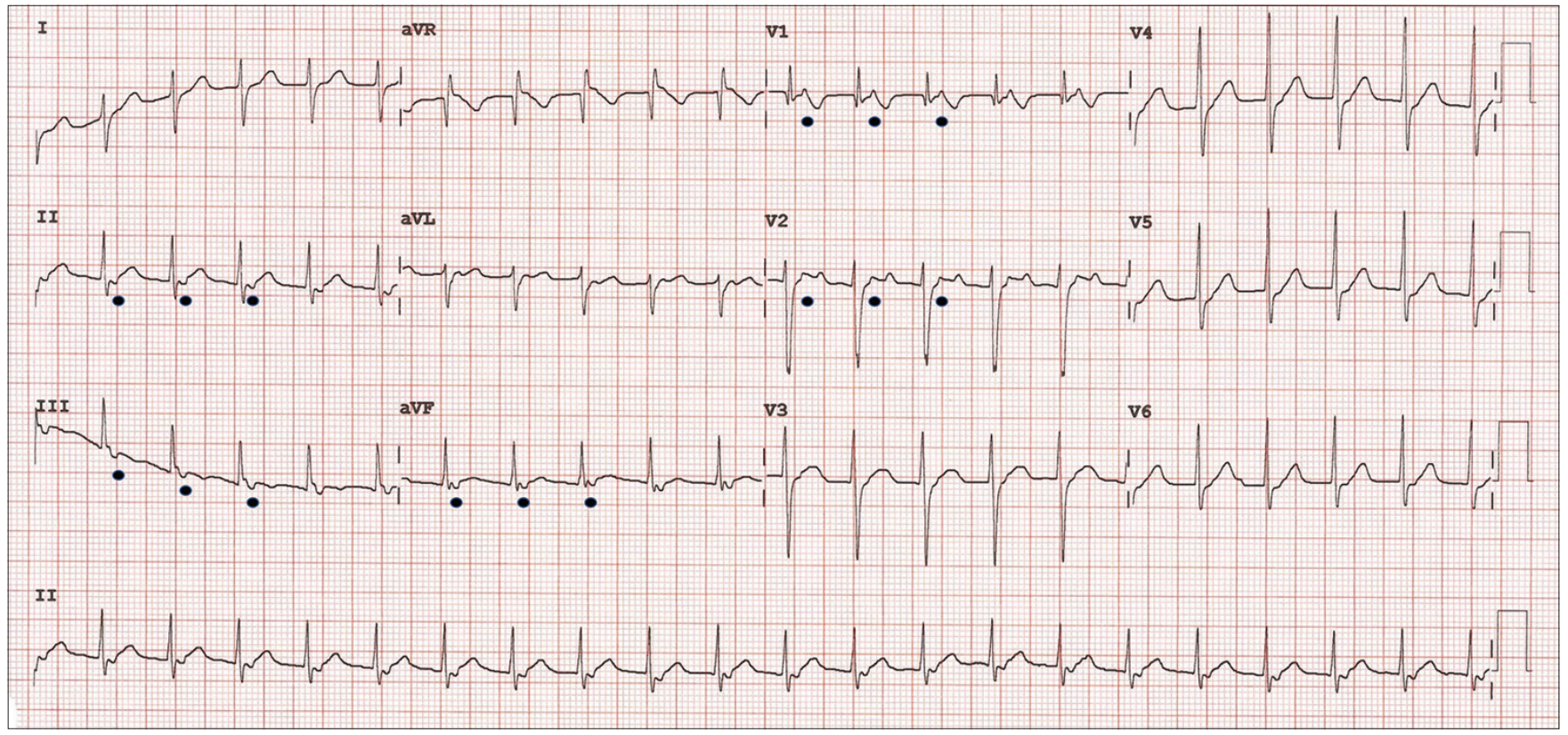

Fig. 1 12-lead ECG on arrival.

\section{CLINICAL PRESENTATION}

A 12-year-old boy presented to the Children's Emergency Department with sudden-onset palpitations that began while he was watching television. He had experienced similar symptoms before, and had been instructed to take his medication as a 'pillin-the-pocket' should they occur. He did not report any chest pain or shortness of breath. His father brought him to the hospital as his symptoms had persisted despite two doses of medications. Clinical examination revealed a well-appearing child with normal heart sounds and a mildly elevated heart rate of 128 beats per minute (bpm). No cardiac murmurs or adventitious lung sounds were heard. His blood pressure and oxygen saturation were within normal limits.

A 12-lead electrocardiogram (ECG) was obtained. What does the ECG (Fig. 1) show?

\section{ECG INTERPRETATION}

The ECG shows tachycardia at a rate of $128 \mathrm{bpm}$. P waves are not visualised preceding each QRS complex in this ECG; instead, retrograde $\mathrm{P}$ waves are seen in leads $\mathrm{V} 1$ and $\mathrm{V} 2$, and in leads II, III and aVF (Fig. 1). These findings suggest that although the heart rate of the patient is slower than expected, he is indeed in supraventricular tachycardia (SVT). However, it would be difficult to determine on surface ECG whether the SVT is an atrioventricular re-entrant tachycardia (AVRT) or atrioventricular nodal re-entrant tachycardia (AVNRT). The heart rate was slower than expected, as the patient had taken beta-blockers prior to arrival at the Children's Emergency. There is no evidence of preexcitation on the ECG at baseline.

\section{CLINICAL COURSE}

Further questioning revealed that the patient had taken a total of $15 \mathrm{mg}$ of propranolol within two hours prior to presentation. He had a known history of recurrent SVT and was on follow-up at the outpatient cardiology clinic. His last transthoracic echocardiogram showed a structurally and functionally normal heart. He had been advised to take propranolol $10 \mathrm{mg}$ on an 'as-needed' basis should initial vagal

${ }^{1}$ Department of Emergency Medicine, ${ }^{2}$ Cardiology Service, Department of Paediatric Subspecialties, KK Women's and Children's Hospital, ${ }^{3}$ Duke-NUS Medical School, Singapore Correspondence: Dr Ronald Ming Ren Tan, Consultant, Children's Emergency, KK Women's and Children's Hospital Singapore, 100 Bukit Timah Road, Singapore 229899. ronald.tan.m.r@singhealth.com.sg 


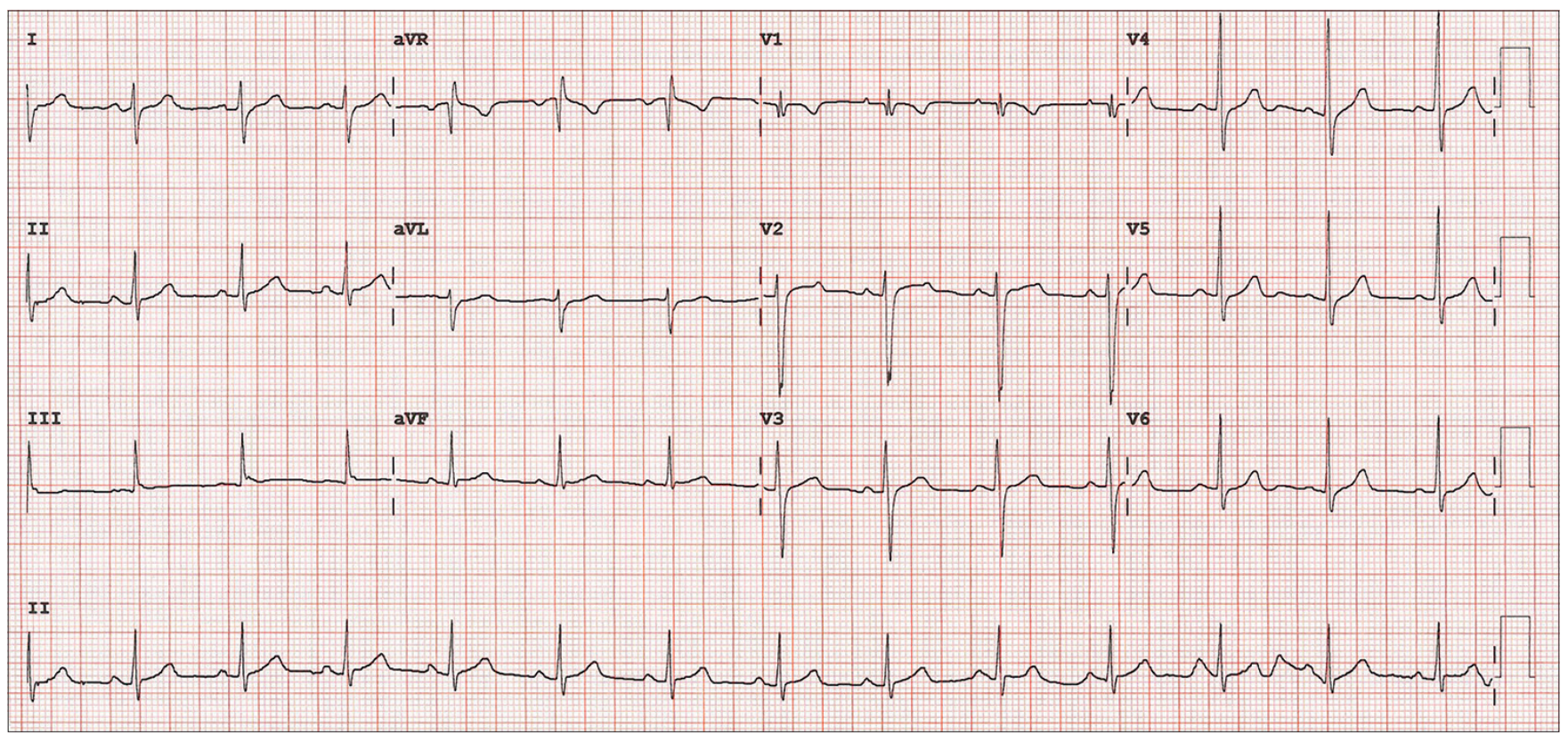

Fig. 2 12-lead ECG after first dose of adenosine shows normal sinus rhythm with no evidence of pre-excitation.

manoeuvres be unsuccessful. As he was haemodynamically stable at the Children's Emergency, vagal manoeuvres were re-attempted. After they were unsuccessful, intravenous adenosine of $0.1 \mathrm{mg} / \mathrm{kg}$ was administered with a rapid saline flush and the rhythm was converted to sinus rhythm. A repeat ECG was obtained (Fig. 2), which showed no retrograde $\mathrm{P}$ waves, normalisation of heart rate and return to normal sinus rhythm. His palpitations resolved and he was discharged after a period of observation, with an early follow-up appointment with the Cardiology clinic.

He subsequently returned to the Children's Emergency eight days later owing to another episode of SVT, which required two doses of intravenous adenosine this time, with a second dose at $0.2 \mathrm{mg} / \mathrm{kg}$, for successful rhythm conversion. Following this second presentation, he was discharged with a regular dose of oral atenolol.

\section{DISCUSSION}

SVT describes a collection of arrhythmias originating from the atria or atrioventricular node and is the most common arrhythmia in the paediatric population, presenting as a narrow complex regular tachycardia with an extremely rapid ventricular rate (usually 160-300 bpm). ${ }^{(1-3)}$ As per the 2020 Singapore Advanced Paediatric Life Support Guidelines, the heart rate in SVT is usually above $180 \mathrm{bpm}$ in children and above $220 \mathrm{bpm}$ in infants. ${ }^{(4)}$ The child is typically otherwise well, with a structurally normal heart. Children with recurrent SVT are frequently managed with rhythm control agents, either with regular or as-needed dosing. ${ }^{(5,6)}$ In patients who have been pre-treated with beta-blockers, special consideration should be taken during ECG interpretation, as the presenting heart rate may be only mildly elevated and the absence of marked tachycardia may prevent physicians from arriving at the correct diagnosis of SVT. Attention should be paid to the presence or absence of $\mathrm{P}$ waves preceding each QRS complex. The clue to the diagnosis of SVT in this case would be the presence of retrograde $P$ waves in leads V1, V2, II, III and aVF. In our approach, we would also look for typical ECG features of specific types of SVT such as the pseudo $r^{\prime}$ waves and the pseudo S waves of AVNRT. Another clue would be a fixed monotonous heart rate at presentation.

In re-entrant tachycardia, electrical impulses from activated myocardial regions re-excite areas with recovered excitability and travel around in a re-entrant circuit to cause rapid ventricular depolarisation in an anterograde manner. ${ }^{(1,2)}$ The atria are depolarised in a retrograde manner by the returning electrical impulses, resulting in the appearance of retrograde $\mathrm{P}$ waves on the ECG. These are commonly seen as inverted $P$ waves in the inferior leads of II, III and aVF and are usually embedded within or after the QRS complex. Rarely, they may even appear before the QRS complex in atypical forms of re-entrant tachycardia. ${ }^{(2,7)}$ The re-entrant circuit is most commonly established via an anatomical accessory pathway in infants, leading to AVRT, and may manifest features of pre-excitation on ECG (e.g. Wolff-Parkinson-White syndrome). ${ }^{(5)}$ In older children, AVNRT is more common and involves a functionally distinct pathway within the atrioventricular node with varying conduction velocities, creating the re-entrant circuit. ${ }^{(1,2)}$ In AVNRT, retrograde $\mathrm{P}$ waves may also be seen, appearing as pseudo $\mathrm{r}^{\prime}$ waves in leads $\mathrm{V} 1$ and $\mathrm{V} 2$ and pseudo $\mathrm{S}$ waves in leads II, III and aVF. More commonly, P waves may be absent on the ECG strip, as they are hidden within the QRS complex. ${ }^{(1,2)}$ In some situations, as in this case, it may be difficult to differentiate between AVRT and AVNRT on surface ECG, and an electrophysiological study may be required if the episodes of SVT are recurrent. In both cases, the SVT may be aborted pharmacologically with adenosine if vagal manoeuvres fail.

Chronic management of SVT is dependent on the frequency of recurrences and severity of symptoms. The evidence for management of recurrent cases with pharmacological agents is not as robust in the paediatric population compared to the adult population. Beta-blockers are generally recommended as a first-line option for control of recurrent SVT, with instruction to 
caregivers to monitor for bradycardia and hypotension presenting as dizziness and lethargy. ${ }^{(6,7)}$ Beta-blockers slow the conduction velocity through the atrioventricular node and block impulses from re-circulating while the other re-entrant pathway remains in refractory period. ${ }^{(6)}$ Daily prophylactic therapy is more efficacious than a single-dose 'as-needed' regime; however, it suffers from poorer compliance and higher risk of adverse effects. ${ }^{(7)}$ Almost all anti-arrhythmic agents, including calcium channel blockers, digoxin, flecainide, amiodarone and sotalol, have been used in the treatment of SVT, although most have a less favourable sideeffect profile and are less commonly used, particularly in the presence of structural heart disease or Wolff-Parkinson-White syndrome. ${ }^{(5,6,8)}$ We recommend that calcium channel blockers be avoided in infants in view of the risk of cardiac decompensation. ${ }^{(9)}$

Catheter ablation is an effective option to consider as it has high success rates, especially in older children, and is recommended in major treatment guidelines for recurrent SVT. It is, however, avoided in infants below one year of age in view of an increased risk of complications with a higher chance of spontaneous resolution. ${ }^{(5,8,10)}$

\section{REFERENCES}

1. Park MK. Cardiac arrhythmias. In: Park MK. Pediatric Cardiology for Practitioners. 4th ed. St Louis: Mosby, 2002: 333-48.
2. Brugada J, Katritsis DG, Arbelo E, et al. 2019 ESC Guidelines for the management of patients with supraventricular tachycardia. The Task Force for the management of patients with supraventricular tachycardia of the European Society of Cardiology (ESC). Eur Heart J 2020; 41:655-720.

3. Spearman AD, Williams P. Supraventricular tachycardia in infancy and childhood. Pediatr Ann 2014; 43:456-60.

4. Lim J. Cardiac arrhythmias and other emergencies. In: Badron J, Lin D, Lwin Z, Ganapathy S, Kok C, eds. Advanced Paediatric Life Support Course (Singapore). Singapore: Singapore Paediatric Society, 2020: 54-72.

5. Brugada J, Blom N, Sarquella-Brugada G, et al. Pharmacological and nonpharmacological therapy for arrhythmias in the pediatric population: EHRA and AEPC-Arrhythmia Working Group joint consensus statement. Europace 2013; 15:1337-82.

6. Salerno JC, Seslar SP. Supraventricular tachycardia. Arch Pediatr Adolesc Med 2009; 163:268-74.

7. Page RL, Joglar JA, Caldwell MA, et al. 2015 ACC/AHA/HRS guideline for the management of adult patients with supraventricular tachycardia: a report of the American College of Cardiology/American Heart Association Task Force on Clinical Practice Guidelines and the Heart Rhythm Society. J Am Coll Cardiol 2016; 67:e27-e115.

8. Richardson C, Silver ES. Management of supraventricular tachycardia in infants. Paediatr Drugs 2017; 19:539-51.

9. Epstein ML, Kiel EA, Victorica BE. Cardiac decompensation following verapamil therapy in infants with supraventricular tachycardia. Pediatrics 1985; 75:737-40.

10. Saul JP, Kanter RJ, Abrams D, et al. PACES/HRS expert consensus statement on the use of catheter ablation in children and patients with congenital heart disease: developed in partnership with the Pediatric and Congenital Electrophysiology Society (PACES) and the Heart Rhythm Society (HRS). Endorsed by the governing bodies of PACES, HRS, the American Academy of Pediatrics (AAP), the American Heart Association (AHA), and the Association for European Pediatric and Congenital Cardiology (AEPC). Heart Rhythm 2016; 13:e251-e89. 


\section{SINGAPORE MEDICAL COUNCIL CATEGORY 3B CME PROGRAMME} (Code SMJ 202201B)

Question 1. Regarding the characteristic electrocardiogram (ECG) features of supraventricular tachycardia (SVT):

(a) P waves may appear as pseudo $r^{\prime}$ or $S$ waves in the QRS complex.

(b) Retrograde P waves can appear before, within or after the QRS complex.

(c) There is QRS concordance in the precordial leads.

(d) Features of pre-excitation may be seen.

Question 2. The following cardiac rhythms are possible differentials for narrow complex tachycardia without apparent $\mathrm{P}$ waves:

(a) Atrioventricular nodal re-entrant tachycardia (AVNRT)

(b) Atrioventricular re-entrant tachycardia (AVRT)

(c) Supraventricular tachycardia

(d) Multifocal atrial tachycardia

Question 3. Regarding supraventricular re-entrant tachycardia:

(a) In AVRT, the atrioventricular node forms one limb of the re-entrant circuit.

(b) AVRT involves an anatomical accessory pathway.

(c) AVNRT is more common in older children.

(d) The SVT may be aborted with adenosine if vagal manoeuvres do not work.

Question 4. Chronic treatment options for SVT include:

(a) Beta-blockers

(b) Calcium channel blockers

(c) Digoxin

(d) Flecainide

Question 5. Regarding SVT in infants:

(a) AVRT is more common than AVNRT.

(b) The ECG may show features of pre-excitation.

(c) Calcium channel blockers should be avoided.

(d) Catheter ablation is safe.

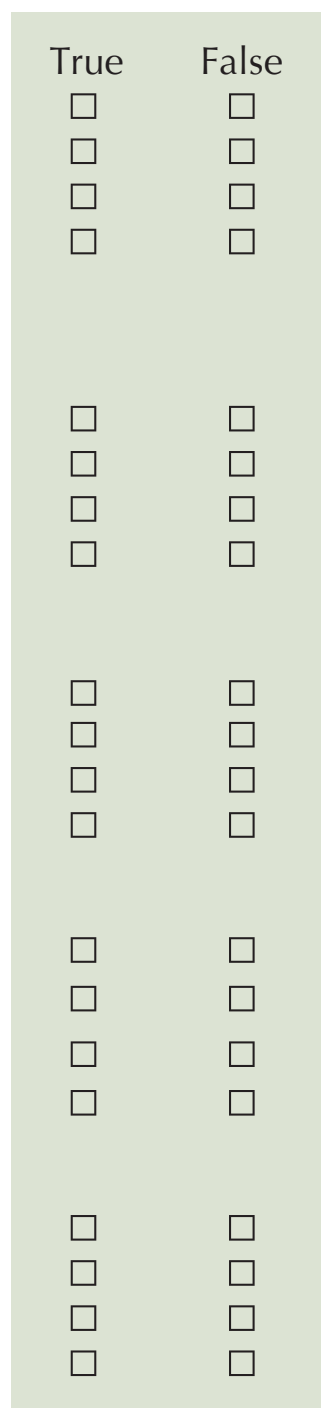

Doctor's particulars:

Name in full:

Specialty:

MCR no.:

Email:

\section{SUBMISSION INSTRUCTIONS:}

Visit the SMJ website: http://www.smj.org.sg/current-issue and select the appropriate quiz. You will be redirected to the SMA login page.

For SMA member: (1) Log in with your username and password (if you do not know your password, please click on 'Forgot your password?'). (2) Select your answers for each quiz and click 'Submit'.

For non-SMA member: (1) Create an SMJ CME account or log in with your SMJ CME username and password (for returning users). (2) Make payment of SGD 21.40 (inclusive of $7 \%$ GST) via PayPal to access this month's quizzes. (3) Select your answers for each quiz and click 'Submit'.

RESULTS:

(1) Answers will be published online in the SMJ March 2022 issue. (2) The MCR numbers of successful candidates will be posted online at the SMJ website by 31 March 2022. (3) Passing mark is $60 \%$. No mark will be deducted for incorrect answers. (4) The SMJ editorial office will submit the list of successful candidates to the Singapore Medical Council. (5) One CME point is awarded for successful candidates. (6) SMC credits CME points according to the month of publication of the CME article (i.e. points awarded for a quiz published in the December 2021 issue will be credited for the month of December 2021, even if the deadline is in February 2022).

Deadline for submission (January 2022 SMJ 3B CME programme): 12 noon, 24 March 2022. 